\title{
Medication reconciliation: ineffective or hard to implement?
}

\author{
Edward Etchells, ${ }^{1,2}$ Olavo Fernandes $s^{3,4}$
}

${ }^{1}$ Centre for Quality Improvement and Patient Safety, University of Toronto, Toronto, Ontario, Canada

${ }^{2}$ Department of Medicine, Sunnybrook Health Sciences Centre, Toronto, Ontario, Canada

${ }^{3}$ Department of Pharmacy, University Health Network, Toronto, Ontario, Canada ${ }^{4}$ Leslie Dan Faculty of Pharmacy, University of Toronto, Toronto, Ontario, Canada

\section{Correspondence to} Dr Edward Etchells, Centre for Quality Improvement and Patient Safety, University of Toronto, Toronto, ON M4N 3M5, Canada;

edward.etchells@sunnybrook.ca

Accepted 5 October 2018 Published Online First 24 October 2018

\section{Sinked}

- http://dx.doi.org/10.1136/ bmjqs-2018-008233

\section{Check for updates}

(C) Author(s) (or their employer(s)) 2018. No commercial re-use. See rights and permissions. Published by BMJ.

To cite: Etchells $E$, Fernandes O. BMJ Qual Saf 2018:27:947-949.
In this issue of BMJ Quality \& Safety, Schnipper et al evaluate the implementation of a multifaceted medication reconciliation intervention at six hospitals using the MARQUIS medication reconciliation implementation toolkit. ${ }^{1}$ The planned intervention included the following elements: hiring or reallocating new staff to obtain medication histories, performing both admission and discharge medication reconciliation, improving access to preadmission medication sources, introducing policy, training staff on obtaining medication histories and patient counselling, implementing a gold standard medication reconciliation process including targeting of high-risk patients, improving healthcare information technology and utilising social marketing and community engagement. The study had many methodological strengths, including independent observers for outcome verification, clinical assessment of medication discrepancies, pragmatic implementation in both community and teaching hospitals, mentored implementation and a large randomly selected patient sample with controls and temporal trending. The main result was that potentially harmful discrepancies did not decrease over time beyond baseline temporal trends (adjusted incidence rate ratio 0.97 per month $(0.86$ to 1.08$), \mathrm{p}=0.53$ ).

One potential explanation for the main result of Multi-Center Medication Reconciliation Quality Improvement Study (MARQUIS) is that multifaceted medication reconciliation interventions are ineffective. We think this is unlikely. While the overall quality of the literature remains mixed, ${ }^{2}$ several well-designed studies demonstrate that medication reconciliation programmes can successfully reduce potentially harmful medication discrepancies, and some studies show downstream benefits on healthcare utilisation. ${ }^{3-5}$ To optimise patient impact, effective medication reconciliation should be embedded in a multifaceted medication management interventional bundle, including interprofessional medication management collaboration, active patient engagement, pharmacist involvement and integration of medication reconciliation into discharge summaries and prescriptions. ${ }^{6}$

A more likely explanation for the main result of the MARQUIS trial is that implementation was difficult. One site dropped out. A second site implemented none of the MARQUIS package, primarily because of the concurrent distraction of implementing a new electronic health record. None of the remaining four sites implemented every element of the planned intervention. The challenges of implementing medication reconciliation in the MARQUIS study resonate with other published implementation reports. ${ }^{7-9}$ Despite these challenges, there were some encouraging signals. Of the four sites that implemented interventions, three observed reductions in potentially harmful discrepancies, consistent with many prior studies of medication reconciliation.

Successful implementation has many active ingredients, although the recipe for success will vary. Greenhalgh's model for diffusion of innovation ${ }^{10}$ suggests 11 features of a change that will increase the likelihood of successful implementation. We have chosen to highlight four of these features in the context of medication reconciliation: relative advantage, low complexity, observability and technical support.

\section{RELATIVE ADVANTAGE}

Relative advantage refers to a clear, unambiguous advantage from the perspective of the adopter. The adopter will judge effectiveness based on the efficient use of the adopter's time, the perceived ease of the 
task or the perceived enjoyment of the task. The original concept of medication reconciliation consisted of identification and resolution of unintended discrepancies between lists of medications at admission, transfer and discharge. ${ }^{11}$ For some adopters, medication reconciliation might still be perceived as a cognitively demanding pharmacological accounting task of cross-checking lists of vitamins and laxatives, with no perceived relative advantage.

One method to enhance relative advantage is to solve an existing problem for the adopter. A fundamental task for hospital-based clinicians is to determine why a patient has come to the emergency room. And, medication-related problems constitute a common cause for emergency room visits. ${ }^{12}$ The diagnosis of a medication-related problem rests on an accurate medication history; yet, accessing community pharmacy patient medication lists can be challenging. One medication reconciliation initiative ${ }^{13}$ addressed this existing barrier to accurate diagnosis by automatically bringing community pharmacy records to the provider, helping the adopter to efficiently detect medication-related problems.

Another method for enhancing relative advantage is to redefine the activity. "Completing medication reconciliation' evokes a tedious, lonely activity of completing check boxes for the purposes of accreditation compliance. 'Making sure our patients are on the best possible medications right now' is potentially more enticing, especially as a team-based activity with the clinical pharmacist. Medication reconciliation should not be conducted in isolation, but instead be part of a comprehensive medication management approach that includes medication appropriateness, safety and efficacy assessments. Rather than simply reordering laxatives off a list, we can ask: 'Does this patient need laxatives? If yes, why? What can be done to reduce the need for laxatives? If laxatives are still required, are these the best ones?' The relative advantage is enhanced by redefining the activity to include therapeutic planning, stewardship, medical education and teamwork.

\section{LOW COMPLEXITY}

Innovative change should not make work more complicated. Unfortunately, medication reconciliation unavoidably involves extra work. ${ }^{14}$ Integration of reconciliation to existing work, such as clinical documentation, medication ordering, discharge summaries and discharge prescriptions, is essential. We are aware of one cumbersome reconciliation 'innovation' that required clinicians to view unmatched lists of home and hospital medications on a computer screen, indicate the desired medications to continue in hospital, print the results, then manually recopy the results onto a paper order sheet. Conversely, intuitive electronic applications that employ user-centred design can simplify and support medication reconciliation work and communication for interprofessional teams, patients and community providers. $^{15}$

\section{OBSERVABILITY}

Innovative change is motivated by seeing observable effects that the world is a better place. Observability means that benefits quickly become visible to adopters. Clinicians are more likely to expend an extra effort if there is an observable downstream benefit to the patient or the system. Medication reconciliation programmes that describe summary reductions in 'potentially harmful medication discrepancies' might not meet the users' need for observable benefits. Observability could be enhanced by sharing local stories of potentially harmful unintentional discrepancies identified by medication reconciliation. For example, our medication reconciliation process recently caught two medication errors that could have led to immediate clinical deterioration of a patient with critical aortic stenosis. Explicit discussion of this patient's case during the next implementation would help to make the benefits of reconciliation observable. Observability can also enhance relative advantage, because many clinicians are motivated by altruism.

\section{TECHNICAL SUPPORT}

Technology is not inherently innovative. ${ }^{16}$ Rather, technology can support, or thwart, the implementation of an innovative change. Schnipper et $a l^{1}$ report two sites with an increase in medication discrepancies after implementing new electronic health records. By contrast, Tamblyn et al ${ }^{13}$ undertook extensive software customisation and design to meet the needs of users trying to complete medication reconciliation, then provided small group training by local champions. This innovative package (some of which included new technology) was associated with a ninefold increase in the odds of completing medication reconciliation, with the most marked impact of the intervention being in the surgical units, with completion rates of $80.7 \%$ in the intervention unit compared with $0.7 \%$ in the control units. ${ }^{13}$

In summary, medication reconciliation can be an effective patient safety intervention. ${ }^{3-5}$ Schnipper $e t$ al have shown that medication reconciliation is not only difficult to implement but also can be successfully implemented. Attention to concepts such as relative advantage, low complexity, observability and technical support may increase the likelihood of successful implementation.

Funding The authors have not declared a specific grant for this research from any funding agency in the public, commercial or not-for-profit sectors.

Competing interests None declared.

Patient consent Not required. 
Provenance and peer review Commissioned; internally peer reviewed.

\section{REFERENCES}

1 Schnipper JL, Mixon A, Stein J, et al. Effects of a multifaceted medication reconciliation quality improvement intervention on patient safety: final results of the MARQUIS study. BMJ Qual Saf 2018;27:954-64.

2 McNab D, Bowie P, Ross A, et al. Systematic review and meta-analysis of the effectiveness of pharmacist-led medication reconciliation in the community after hospital discharge. BMJ Qual Saf 2018;27:308-20.

3 Gillespie U, Alassaad A, Henrohn D, et al. A comprehensive pharmacist intervention to reduce morbidity in patients 80 years or older: a randomized controlled trial. Arch Intern Med 2009;169:894-990.

4 Ravn-Nielsen LV, Duckert ML, Lund ML, et al. Effect of an in-hospital multifaceted clinical pharmacist intervention on the risk of readmission: a randomized clinical trial. JAMA Intern Med 2018;178:375-82.

5 Mekonnen AB, McLachlan AJ, Brien JA. Effectiveness of pharmacist-led medication reconciliation programmes on clinical outcomes at hospital transitions: a systematic review and meta-analysis. BMJ Open 2016;6:e010003.

6 Baker M, Bell CM, Xiong W, et al. Do combined pharmacist and prescriber efforts on medication reconciliation reduce postdischarge patient emergency department visits and hospital readmissions? J Hosp Med 2018;13:152-7.

7 Coffey M, Cornish P, Koonthanam T, et al. Implementation of admission medication reconciliation at two academic health sciences centres: challenges and success factors. Healthc $Q$ 2009;12 Spec No Patient:102-9.
8 Holbrook A, Bowen JM, Patel H, et al. Process mapping evaluation of medication reconciliation in academic teaching hospitals: a critical step in quality improvement. BMJ Open 2016;6:e013663.

9 Pevnick JM, Shane R, Schnipper JL. The problem with medication reconciliation. BMJ Qual Saf 2016;25:726-30.

10 Greenhalgh T, Robert G, Macfarlane F, et al. Diffusion of innovations in service organizations: systematic review and recommendations. Milbank Q 2004;82:581-629.

11 Rozich JD, Resar RK. Medication safety :one organization's approach to the challenge. J Clin Outcomes Manage 2001;8:27-34.

12 Zed PJ, Abu-Laban RB, Balen RM, et al. Incidence severity and preventability of medication-related visits to the emergency department: a prospective study. CMAJ 2008;178:1563-9.

13 Tamblyn R, Winslade N, Lee TC, et al. Improving patient safety and efficiency of medication reconciliation through the development and adoption of a computer-assisted tool with automated electronic integration of population-based community drug data: the RightRx project. J Am Med Inform Assoc 2018;25:482-95.

14 Meguerditchian AN, Krotneva S, Reidel K, et al. Medication reconciliation at admission and discharge: a time and motion study. BMC Health Serv Res 2013;13:485.

15 Schnipper JL, Hamann C, Ndumele CD, et al. Effect of an electronic medication reconciliation application and process redesign on potential adverse drug events: a clusterrandomized trial. Arch Intern Med 2009;169:771-80.

16 Mehta SJ, Asch DA. Does using an iPad make an intervention innovative? Ann Intern Med 2018;168:592-3. 